[Original]

\title{
Effects of Screen Size and Task Difficulty on Vigilance Performance of Older Adults
}

\author{
Masahiro HASHIMOTO ${ }^{1}$, Masaharu KUMASHIRO² and Shinji MIYAKE ${ }^{3}$ \\ ${ }^{1}$ Bio-information Research Center, University of Occupational and Environmental Health, Japan. \\ Yahatanishi-ku, Kitakyushu 807-8555, Japan \\ ${ }^{2}$ Department of Ergonomics, Institute of Industrial Ecological Sciences, University of Occupational and \\ Environmental Health, Japan. Yahatanishi-ku, Kitakyushu 807-8555, Japan \\ ${ }^{3}$ Department of Environmental Management II, School of Health Sciences, University of Occupational \\ and Environmental Health, Japan. Yahatanishi-ku, Kitakyushu 807-8555, Japan
}

Abstract: This paper describes an experiment to elucidate the effects of aging on vigilance performance with VDTs. In addition, the experiment was undertaken to evaluate whether the aging effects are affected by the degree of task difficulty and by the screen size of the VDTs. Forty healthy male volunteers were studied in two age groups of 20 participants. In the experiment, the participants were required to perform vigilance tasks, which were presented either on a conventional 17-inch display or a large-sized 110-inch display. The 60-minute task period was divided into three 20-minute phases assigning the tasks with two scenarios of different degrees of difficulty. Performance was measured using reaction time for detection and number of detection errors. The results pointed out three effects: (1) the performance of the vigilance tasks deteriorated more markedly among the older adults than among the younger adults; (2) the between-screen differences on the vigilance performance were significant for the older adults, but not for the younger adults; (3) the effect of screen size was amplified by increasing the degree of task difficulty. These data indicate that screen size and task difficulty have an effect on vigilance performance with VDTs of older adults.

Key words: vigilance performance, display size, task difficulty, older adult.

(Received 20 August 2003, accepted 1 October 2003 )

\section{Introduction}

Visual display terminals (VDTs) have been introduced into a wide variety of occupational settings. Since the ratio of older adults in the workforce is growing, it is highly likely that older workers will need to interact with VDTs to perform their jobs. Since visual perform- 
ance in VDT work environments depends on at least two visual functions that are known to be age sensitive that is, the latency and speed of saccadic eye movements, and the useful field of view, interaction with VDTs may have a negative impact on the work performance of older workers [1].

In addition, many vigilance activities involving VDT operation require the performance of several tasks simultaneously, and thereby attention is divided among different information.

Age related decrements in dual task capabilities, however, have been demonstrated in earlier papers [2]; older adults are more likely to have difficulties in dual-task performance with a VDT than younger adults. Moreover, given that age related differences are magnified by increasing the complexity of a task [3], it is conceivable that the aging effect on visual performance becomes significant when constituent tasks demand more complex operations.

On the other hand, large-sized VDTs have recently become more popular in large-scale, real-time operating environments, such as traffic control centers or nuclear power facilities, where sustained visual monitoring is required during the performance of a task. To date, most research on VDT work has focused on VDT workstations where CRT monitors under 20 inches of screen size are used on a desk. Little attention has been given to the effects of large-sized VDTs of over 100 inches on visual performance, especially for older adults.

Therefore, the purpose of the present study was to elucidate the effects of aging on vigilance performance with VDTs. In addition, the study was undertaken to evaluate whether the aging effects are affected by the degree of task difficulty and by the screen sizes of the VDTs.

\section{Methods}

\section{Participants}

Forty male volunteers were recruited as paid participants and studied in two age groups of 20 participants (age, less than 30 years and more than 55 years). The mean age of the older group was 61.9 years (range 55-68, SD 3.2); the mean age of the younger group was 21.5 years (range 20-28, SD 1.7).

All participants reported themselves to be in good health and were free from any eye diseases or undergoing medical treatment. They were screened for a far binocular visual acuity not greater than 1 minute of arc. All participants were instructed to wear their current spectacle correction, if any, during the tasks. Four older participants, who required refractive correction, wore their habitual reading glasses during the tasks. We made no effort to insure that their correction was in fact optimal. Instead, we decided that it was rather important to establish the visual condition likely to be encountered in daily situations.

Participants were required to have at least a high school diploma. None had any previous computer experience with VDTs. The nature and purpose of the study were explained in a letter personally inviting each subject to participate and also again during the interview. All 
participants agreed to participate in the experiment and gave their informed consent.

Tasks

Experimental tasks simulated a large-scale, real-time control environment. The tasks, which were simultaneously performed on a screen, consisted of a monitoring task and a fuel management task from a revised version of the Multi-Attribute Task [4] programmed by Shinji Miyake. The content of each task was as follows.

\section{Monitoring task}

In this task, four gauges with fluctuating pointers and two alarms were displayed on the left of the screen. The participants were required to try to respond quickly by pressing one of the six designated keypads on a keyboard if a gauge's pointer stopped fluctuating or a light went on. If participants did not respond within 10 seconds, the gauge or the light was automatically reset and it was credited with a detection error. Each keypad corresponded to a specific gauge or the light. The performance measures for this task included reaction time for detection (pressing the correct key) and number of detection errors (failing to reset).

\section{Fuel management task}

In this task, six fuel tanks connected by eight pumps were presented in the center of the screen. The participants were required to monitor fuel level required for each tank. They refueled by pressing a designated keypad to keep fuel at required levels. Each keypad corresponded to a specific pump. If fuel in a tank fell below required levels, an alarm went off until the fuel level was restored to the required levels. The performance measures for this task were the number of keystrokes and alarms which went off during the task.

\section{Apparatus}

The experimental tasks were presented either on a 17-inch CRT display (Mitsubishi RD17 Y) or a 110-inch rear projection screen(Hitachi C110-1122R), as shown in Fig. 1. The luminances of the brightest area for the 17 -inch and 110 -inch screens were $53 \mathrm{~cd} / \mathrm{m}^{2}$ and 20 $\mathrm{cd} / \mathrm{m}^{2}$, respectively, while those of the darkest area were $2 \mathrm{~cd} / \mathrm{m}^{2}$ and $1 \mathrm{~cd} / \mathrm{m}^{2}$, respectively. The illuminations for the 17-inch and 110-inch screen conditions were $250 \mathrm{~lx}$ and $85 \mathrm{~lx}$ on the screen, respectively, while those on the keyboard were identical (590 lx).

The 17-inch display was located at a mean preferred viewing distance of $0.6 \mathrm{~m}$ as set by each subject, while the 110-inch display was located at a mean distance of $4 \mathrm{~m}$ so that an equal screen area of $30^{\circ}$ (horizontal) $\times 20^{\circ}$ (vertical) was visible from the positions of the participants under the two screen conditions. Before the experiment, the participants were asked to adjust the workstation to their individual preferences. Mean preferred heights for the seat and for the keyboard were $44.9 \mathrm{~cm}$ and $68.1 \mathrm{~cm}$, respectively. 

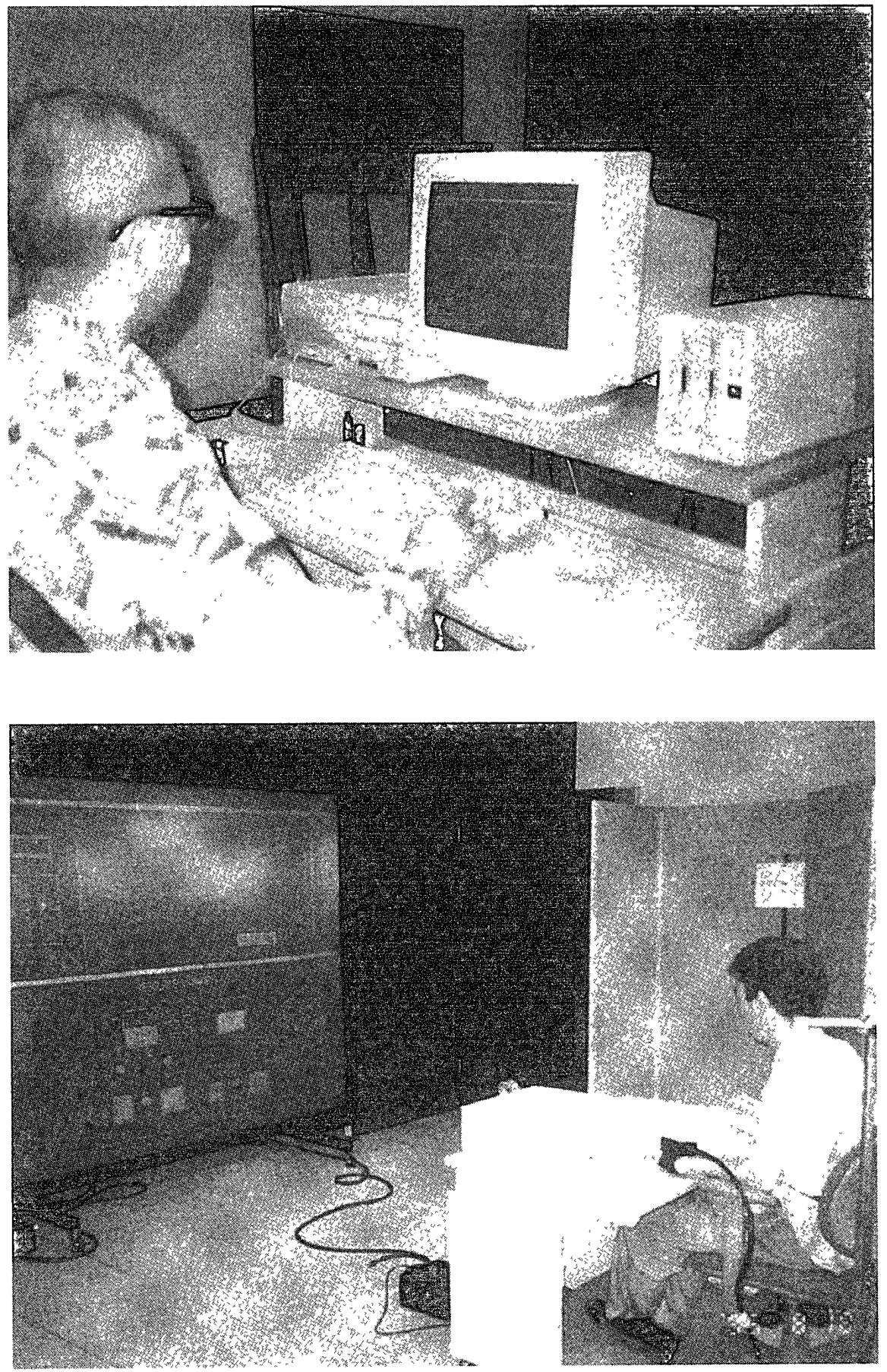

Fig. 1. Experimental settıngs.

A: 17-inch CRT display (Mitsubishi RD17Y)

B: 110-inch rear projection screen (Hitachi C110-1122R)

\section{Procedure}

Each subject was required to participate for two days in the experiment. Both of the screens were used on each day. The order of the screens was counterbalanced across the 
participants. An extra day was needed before the first day of testing to familiarize the participants with the experimental settings and the various apparatuses used in the experiment. On that day, the participants were allowed plenty of practice time until they demonstrated that they could perform the tasks without assistance. As expected, the older participants spent more time practicing than the younger participants.

In the experiment, the participants were required to perform the monitoring task in combination with the fuel management task for 60 minutes. The 60 -minute task period was divided into three 20-minute phases assigning the fuel management task with two scenarios of different degrees of difficulty. The two scenarios were designed to represent an easy situation and a demanding situation. The different scenarios were produced by changing the consumption rate of the fuel. The easy scenario was allocated to the first and final phase and the demanding scenario to the second phase.

To confirm the degree of task difficulty, subjective workload was assessed using the NASA Task Load Index scale(TLX) at 20-minute intervals. The fuel management task in the second phase produced higher ratings on all dimensions of the TLX workload $(\mathrm{F}(2,117)$ $=20.5, P<0.001)$. Larger differences between the phases were observed in effort and frustration. Although large individual differences were observed in ratings on workload, all participants perceived a higher workload at the second phase irrespective of the screen size. Consequently, it is clear that all participants experienced different degrees of task difficulty.

Analysis of variance(ANOVA) was applied to test the effects of age group (older and younger), screen size(17 inches and 110 inches), task difficulty (easy and demanding), and their interaction for each dependent variable (reaction time, detection errors, keystrokes, and alarms). In each group, values within each 20-minute phase in each screen condition were averaged for each dependent variable.

\section{Results}

\section{Monitoring task}

The performance measures on the monitoring task included reaction time and number of errors. Reaction time was evaluated for trials on which the correct detection was made. These data for each 20-minute phase are shown in Fig. 2. ANOVA revealed a significant effect for the age group $(\mathrm{F}(1,38)=39.8, P<0.0001)$. As expected, reaction time for detection was characteristically longer for the older group than for the younger group. With respect to the older group, the effects of screen size and task difficulty were statistically signifi$\operatorname{cant}(\mathrm{F}(1,114)=12.1, P<0.001, \mathrm{~F}(2,114)=25.5, P<0.001$, respectively). The interaction of these factors was also significant $(\mathrm{F}(2,114)=8.9, P<0.005)$. Reaction time increased when the demanding scenario was introduced using the 17 -inch screen, whereas reaction time for the 110 -inch screen was generally unaffected by the task difficulty. On the other hand, no statistically significant effects were observed for the screen size or the task dif- 


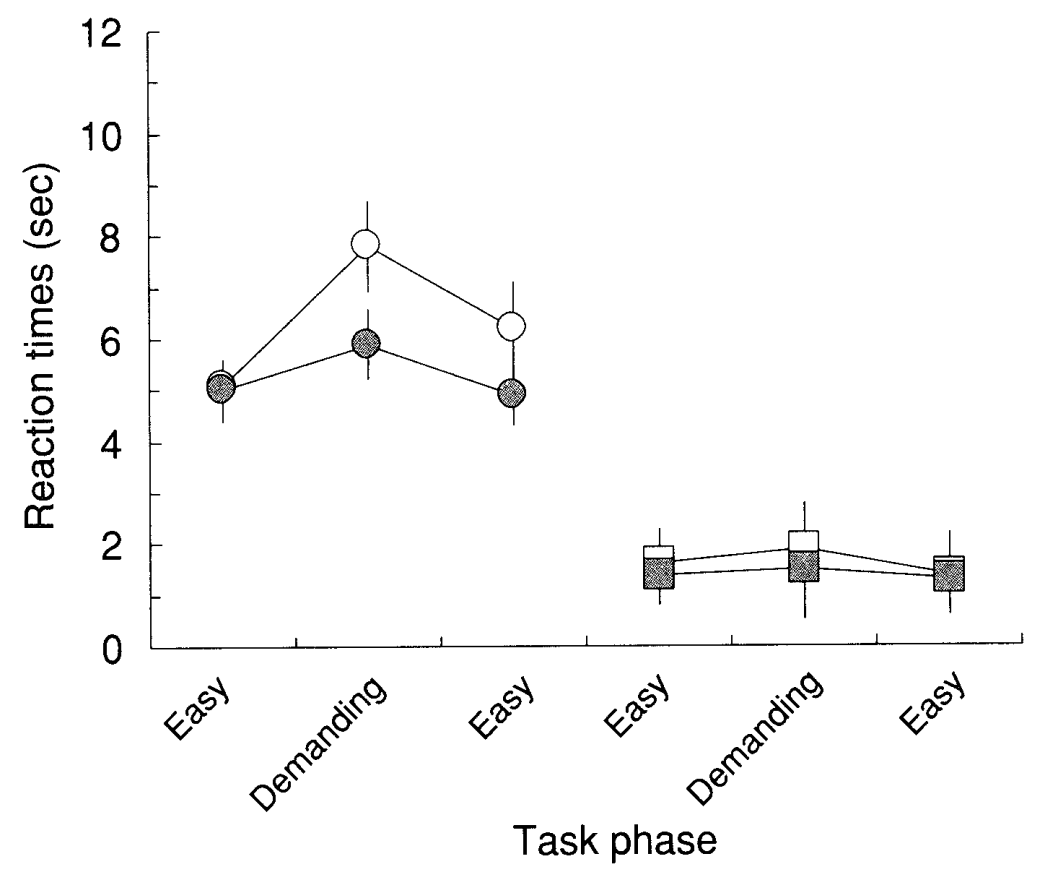

Fig. 2. Reaction times (means \pm SD) plotted as a function of age group (older and younger), screen size (17 inches and 110 inches) and task difficulty (easy and demanding).

$\multimap-$ : older (17 in.), $-\bigcirc$ : older (110 in.), $\square-:$ younger $(17$ in. $)$,

- younger (110 in.).

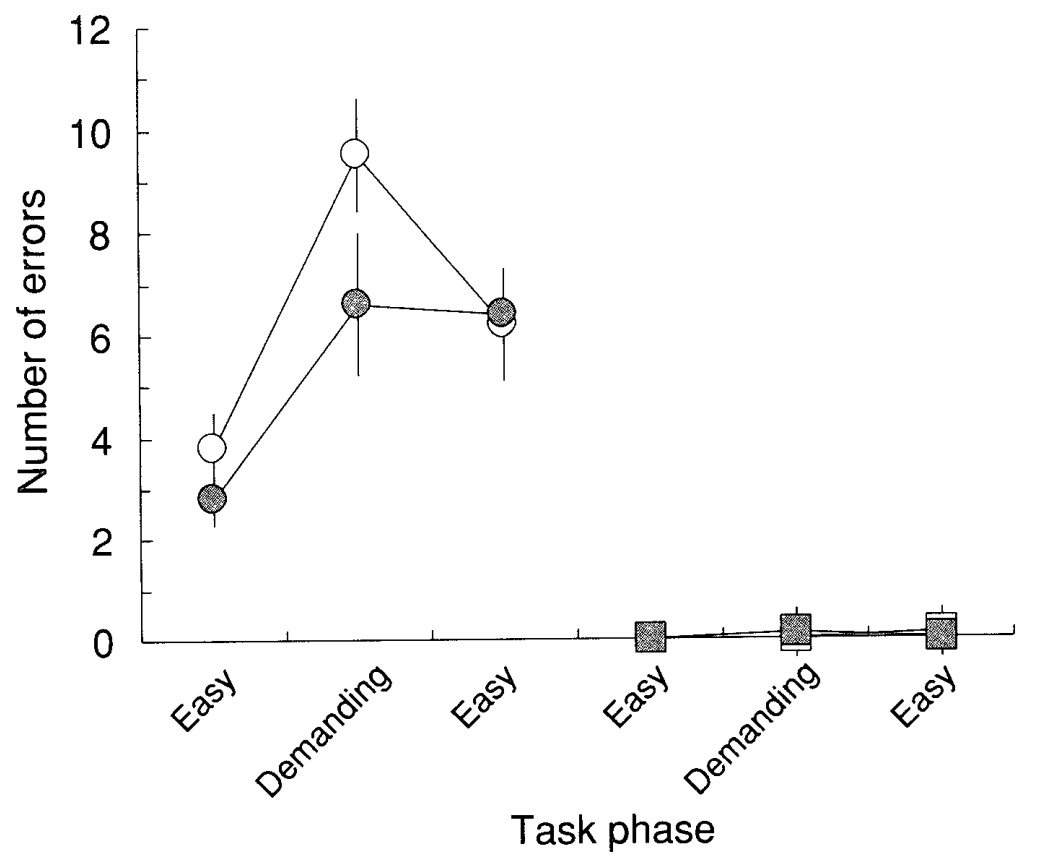

Fig. 3. Number of errors (means $\pm S D$ ) plotted as a function of age group, screen size and task difficulty.

$\multimap-: \operatorname{older}(17$ in. $),-\bigcirc$ : older $(110$ in. $), \square-:$ younger $(17$ in.),

- younger (110 in.). 
ficulty in the younger group. The younger participants showed stable reaction times over the task period for either screen. Age differences in reaction time were larger when the task was performed on the 17-inch screen and became more demanding.

Detection errors for the monitoring task were evaluated for trials in which participants failed to detect the gauge shift. Fig. 3 shows the mean number of errors as a function of age group and the screen size. ANOVA revealed a significant effect for each age group $(\mathrm{F}(1$, $38)=32.3, P<0.0001)$. More errors were committed among the older group than among the younger group. With respect to the older group, the effects of screen size and task difficulty were statistically significant $(\mathrm{F}(1,114)=18.8, P<0.001, \mathrm{~F}(2,114)=25.9, P<0.001$, respectively). The interaction of these factors was also significant $(\mathrm{F}(2,114)=18.3, P<$ $0.005)$. On the other hand, no statistically significant effects were observed for the screen size or the task difficulty for the younger group. Only one of the younger participants failed to detect the signals over the task period. Just as with the results of reaction time, age differences in detection errors were larger when the task was performed on the 17 -inch screen and became more demanding.

\section{Fuel management task}

The performance measures on the fuel management task included a number of alarms and

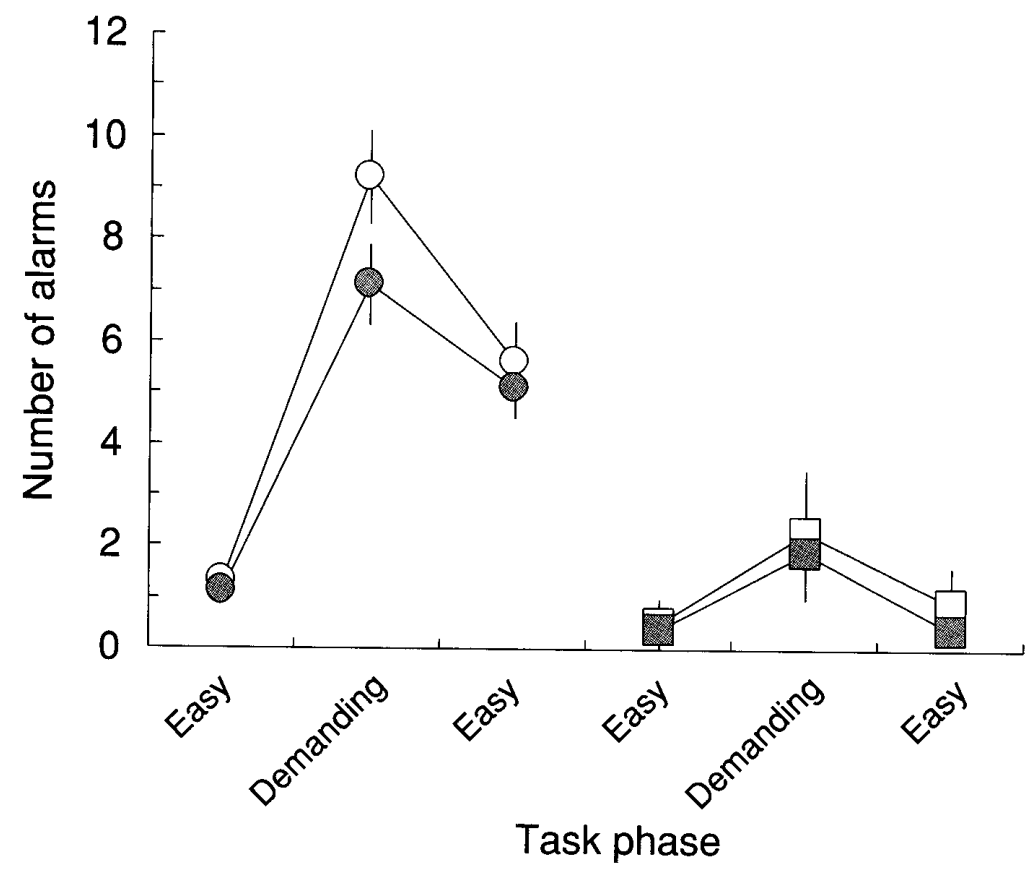

Fig. 4. Number of alarms (means $\pm S D$ ) plotted as a function of age group, screen size and task difficulty.

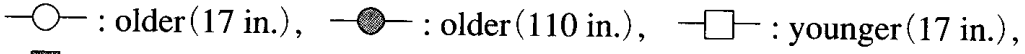

- younger(110 in.). 
keystrokes. The number of alarms was evaluated for trials in which the alarm went off. There was a significant effect for both age groups $(\mathrm{F}(1,38)=31.3, P<0.0001)$, as illustrated in Fig. 4. More alarms went off in the case of the older group during the task than for the younger group. With respect to the older group, a significant interaction emerged between the screen size and the task difficulty $(\mathrm{F}(2,114)=11.4, P<0.005)$. Performance on the fuel management task deteriorated more markedly when presented on the 17 -inch screen as the task became demanding. On the other hand, performance by the younger group also deteriorated under the same condition, but no statistically significant effects were observed for the screen size or the task difficulty. Consequently, age differences in respect to the number of alarms were enlarged by presenting the demanding task on the 17-inch screen.

The number of keystrokes was evaluated for values averaged within each 20 -minute phase. A main effect for the age group was found $(\mathrm{F}(1,38)=26.2, P<0.001)$. Fewer keystrokes were recorded for the older group than for the younger group. There was also a significant main effect for the task difficulty $(\mathrm{F}(2,114)=13.1, P<0.005)$. As shown in Fig. 5 , the second phase, which was the demanding phase, produced a greater increase in the number of keystrokes than did the other phases with the easy scenario for the younger group. The number of keystrokes was generally affected by screen size, but the between-screen differences were not statistically significant for both age groups.

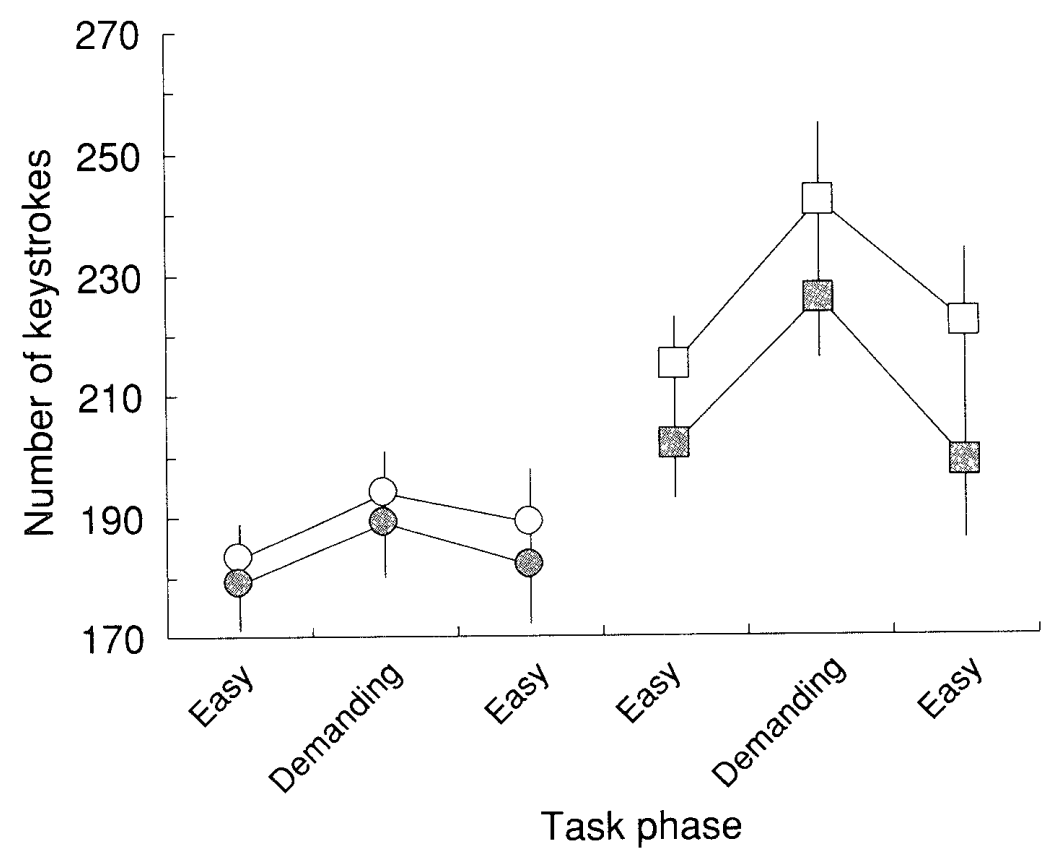

Fig. 5. Number of keystrokes (means $\pm S D$ ) plotted as a function of age group, screen size and task difficulty.

$\multimap-:$ older $(17$ in.), $\bigcirc-$ : older $(110$ in. $), \square-$ : younger(17 in.),

- younger (110 in.). 


\section{Discussion}

The purpose of this study was to examine the effects of aging, screen size and task difficulty on vigilance performance with VDTs. The current study pointed out age differences in the performance of vigilance tasks. As might be expected, the older participants had more difficulty in performing the tasks than did the younger participants. Aging effects were observed for both the monitoring task and the fuel management task. The older participants had longer reaction times and committed more detection errors than did the younger participants for the monitoring task. The older participants also had more alarms and fewer keystrokes for the management task, showing that the older participants failed to keep fuel at the required levels. The results are in accordance with the results of previous studies which investigated the relationship between aging and work performance [5]. Difficulties in the vigilance performance of the older adults could be partly due to a slowing in information processing speed $[6-8]$, the decline of visual perception $[9,10]$, or both.

Furthermore, the data from the present study indicated that the negative effect of age on vigilance performance was significantly affected by the degree of task difficulty; age differences in reaction times and detection errors were greater for the task with the demanding scenario than that with the easy scenario. Therefore, the negative effect of age seems to be exaggerated when tasks demanded sustained attention. These data are consistent with the results of the previous studies that showed age differences in performance of sustained attention tasks [11]. Our results mean that older adults may be placed at a disadvantage when they are working in VDT environments, such as traffic control centers or nuclear power facilities, where sustained monitoring is required.

Finally, making the present study more important was that the screen size of VDT affected vigilance performance for both detection rate and accuracy of signals. Interestingly, the effect was only significant for the older participants; larger screen size resulted in shorter reaction times and fewer detection errors. Moreover, the screen size effect for the older participants was affected by the degree of task difficulty. When the task became more demanding, the screen size effect on vigilance performance was amplified. Since increasing the difficulty of tasks leads to greater difficulties in allocating attention to different tasks [12], this result could be partly attributed to the decline in attention due to advanced age [11]. In addition, and more importantly, there is a deterioration of visual accommodation due to changes in the normal aging eye [13]. It has been confirmed that the average distance of the near point increases from $8 \mathrm{~cm}$ at age 16 to $100 \mathrm{~cm}$ at age 60 . This loss of accommodative ability to focus the eyes on near objects requires an increase in the distances of objects to be in focus. In the present study, the participants were asked to adjust the location of the 17-inch screen to their individual preferences during the practice session. The average distances for the older participants and younger participants were the same distance of $60 \mathrm{~cm}$. The lack 
of previous computer experiences for the older participants, however, could have made it difficult to adjust the screen to their most optimal position. As a consequence, the older participants might have experienced difficulty performing the 60-minute vigilance tasks with the 17 inch screen. Therefore, more attention should be given to the viewing distances of VDTs as a factor that could modulate age related effects deteriorating visual performance with VDTs.

\section{Conclusion}

The findings of this study are significant in three respects: first, the performance on the vigilance tasks deteriorated more markedly among the older adults than the younger adults. Second, the between-screen differences on the vigilance performance were significant for the older adults, but not the younger adults. Third, the effect of screen size was amplified by increasing the degree of task difficulty.

Before VDTs can be successfully introduced into occupational settings, it will be necessary to understand the effects of screen size and task difficulty on VDT work, particularly for older adults who have age related decrements in visual function. Evidence presented here indicates that vigilance performance at VDT work of older adults may be more efficient with a large-sized display than with a conventional display when a task becomes demanding, but large age differences were still observed in regard to performance.

In summary, this study yielded data to support the significant effects of screen size and task difficulty on vigilance performance with VDTs, especially for older adults. Consequently, it is suggested that the presentation of VDT information should be made on largesized screen to improve vigilance performance for older adults.

\section{Acknowledgment}

This work was supported by a grant from the Association of Employment for Senior Citizens of Japan awarded to Masaharu Kumashiro. The authors would like to thank Hitachi Co. Ltd. for providing the 110-inch display.

\section{References}

1. Scialfa CT \& Thomas DM (1994): Age differences in same-different judgments as a function of multidimensional similarity. J Gerontology 49: $173-178$

2. Brouwer WH, Waterink W, van Wolffelaar PC \& Rothengatter T (1991): Divided attention in experienced young and old drivers: Lane tracking and visual analysis in a dynamic driving simulator. $\mathrm{Hu}$ man Factors 33: $573-582$

3. Cerella J (1985): Information processing rates in the elderly. Psychological Bulletin 98: 67-83

4. Comstock JR \& Arnegard RJ (1992): The multi-attribute task battery for human operator workload 
and strategic behavior research. Tech. Memorandum VA: NASA Langley Research Center IP Hampton 104174

5. Sharit J \& Czaja SJ (1994): Aging, computer-based task performance, and stress: issues and challenges. Ergonomics 37: 559-577

6. Salthouse TA (1985): Speed of behavior and its implications for cognition. In Handbook of Psychology and Aging. Van Nostrand Reinhold, New York pp 400-426

7. Czaja SJ \& Sharit J (1993a): Stress reactions to computer interactive tasks as a function of task structure and individual differences. Int J Human Computer Interaction 5: 1-22

8. Czaja SJ \& Sharit J (1993b): Age differences in the performance of computer based work. Psychology Aging 8: $59-67$

9. Cerella J, Poon LW \& Williams D (1982): Age and iconic read out. J Gerontology 37: 197-202

10. Weale RA (1986): Aging and vision. Vision Research 26: 1507-1512

11. Parasuranam R \& Giambra L (1990): Skill development in vigilance: effects of event rate and age. Psychology Aging 6: 155-169

12. Craik FI \& McDowd JM (1987): Age differences in recall and recognition. J Experimental Psychology: Learning, Memory and Cognition 13: 474-480

13. Grandjean E (1986): Fitting the task to the man -an ergonomic approach. Taylor \& Francis, London p 119 
画面サイズと課題難易度が高齢者の計器監視作業遂行能力に及ぼす影響

橋本 正浩1，神代 雅晴 ${ }^{2}$, 三宅 晋司 ${ }^{3}$

${ }^{1}$ 产業医科大学 生体情報研究センター

${ }^{2}$ 産業医科大学 産業生態科学研究所 人間工学教室

${ }^{3}$ 産業医科大学 産業保健学部 第 2 環境管理学講座

要旨： 本研究は, 計器監視作業遂行能力に及ぼす加齢影響を実験的に明らかにすることを目 的とし,加えてここの加齢影響が VDT の画面サイズや課題難易度によってどの程度变 化するのかについても検討した. 高齢男性および若年男性各 20 人を対象に, 計器監視

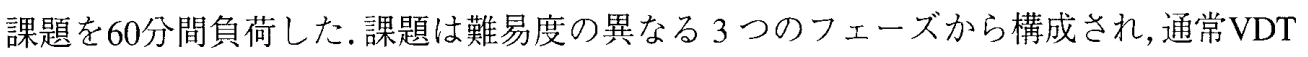
画面もしくは大型スクリーン上で呈示された.作業遂行能力は, 計器異常の検出に要 した時間と見落とし回数により評価した。その結果, 以下の 3 点が明らかになった。

1. 計器監視作業遂行能力は, 若年被験者に比較して, 高齢被験者で著しく低下した.

2.作業画面サイズの違いは, 高龄被験者の作業遂行能力にのみ影響を及ばした。

3.作業画面サイズの影響は, 課題難易度の増加に伴い拡大した。

これらの結果から, 画面サイズと課題難易度は, 高齢者の計器監視作業遂行能力に影 響を及ぼす要因であることが示唆された。

キーワード：計器監視作業, 画面サイズ, 課題難易度, 高齢者.

J UOEH（産業医大誌）25（4）:375-386（2003） 